\title{
Effect Carrier Agent Formulation in Drying Rate and Antioxidant Activity of Roselle Extract
}

\author{
Febiani Dwi Utari $^{1 *}$, Mohammad Djaeni ${ }^{1 *}$, Wahyu Zuli Pratiwi ${ }^{1}$, Muhammad Alver Syahputra ${ }^{1}$, and Uma Fadzilia Arifin ${ }^{1}$ \\ ${ }^{1}$ Department of Chemical Engineering, Faculty of Engineering, Diponegoro University Jl. Prof. Soedarto, SH, Tembalang, \\ Semarang, Indonesia 50275
}

\begin{abstract}
Roselle (Hibiscus sabdarifa $L$ ) contains anthocyanins as the natural colorant and antioxidant. Drying the roselle extract was aims to produce the dry product that easy consumption as antioxidant. The carrier agent was added in roselle extract to improve the drying rate and maintain the nutritional value. This research studied the effect of carrier agent in drying rate and antioxidant activity. The method consists of two step involving roselle extraction using ultrasonic and the drying process. The roselle extraction by ultrasonic use the water as the solvent. The carrier agent $(0 \%, 5 \%, 10 \%$ of maltodextrin) was added in roselle extract. The mixture was then dried in tray dryer dehumidification using zeolite in drying temperature 50,60, and $70^{\circ} \mathrm{C}$. As the response, the moisture content was observed by gravimetry every 15 minutes for 150 minutes. The result showed that Page model was fitted to determine the constant of drying rate. Higher concentration of carrier agent enhanced the moisture evaporation process. Based on the DPPH analysis, the degradation of antioxidant activity in temperature $70^{\circ} \mathrm{C}$ was 2.14 times higher than in temperature $50^{\circ} \mathrm{C}$. As the conclusion, addition of maltodextrin can speed up the drying process and retain the antioxidant activity of.
\end{abstract}

\section{Introduction}

The roselle (Hibiscus sabdariffa Linn.) calyces has the several function, as the antioxidant [1], antimicrobial activity [2], immunoprotective [3] and natural colorant [4]. The antioxidant compound in roselle stronger than commercial antioxidants such as Butylated Hydroxyanisole (BHA) and $\alpha$-tocopherol (TOCO) [5]. Anthocyanins and phenols are the main bioactive compounds in Roselle calyces. The concentration of anthocyanin and phenols in roselle depend on the cultivation and extraction process [6].

Study about roselle calyces extraction using water as the solvent resulted $502.33 \pm 0.52 \mathrm{mg}$ of anthocyanins [7]. Antioxidant compound including anthocyanin has been understood well as not stable because of the high reactivity and easy to degrade $[8,9]$. The drying process is the option to produce the stable form of roselle extract and prolong the storage life.

The drying process with addition of carrier agents can reduce the stickiness surface of liquid products $[10,11]$. The most common carrier agents used in food product is maltodextrins. Maltodextrin is a hydrolyzed starch that gives the advantages such as low cost, good aroma and flavor and low viscosity at high-solids concentrations [12].

Several researcher using maltodextrin in food product drying. Addition 3\% maltodextrin in freeze drying improving color stability of roselle anthocyanin powder [13]. Addition $15 \%$ maltodextrin in drying tamarind pulp at drying temperature $70^{\circ} \mathrm{C}$ had the highest acceptance score [14]. Maltodextrin can retain the color quality of roselle extract drying [11]. In addition, maltodextrin (DE 20) stabilizing the anthocyanin pigments under storage condition [15].

Based on the study, there is a hard information on antioxidant activity degradation of roselle extract dried with carrier agents such as maltodextrin. This work aims to produce the dried roselle extract with the good antioxidant activity. The effect of addition maltodextrin and drying temperature is evaluated. The experimental results are fitted to several thin layer model to describe the drying phenomenon.

\section{Materials and Methods}

\subsection{Roselle extract preparation}

The roselle (Hibiscus sabdariffa Linn.) calyces variety were red roselle that obtained from a herbal medicine market in Solo, Indonesia. The roselle calyces (dry) was milled until the uniform size $(0.25 \mathrm{~mm})$. The roselle extraction based on previously extraction method with several modifications [7]. In this study, the extraction process was carried out using ultrasonic system

Corresponding author: febianidu@gmail.com,moh.djaeni@live.undip.ac.id 
(Branson, $2510 \mathrm{MT}$ ). Water (solvent) and roselle calyces mass to water volume ratio were $1: 10$. The roselle extract was then filtered to separate the filtrate and cake.

\subsection{Carrier agent formulation}

Carrier agent was added in roselle extract to improve the drying rate. The carrier agent was maltodextrin (food grade) with DE 15 . The carrier agent portion was $0 \%$, $5 \%, 10 \%$ of the total mixture. The mixture was stirred using stirrer speed $700 \mathrm{rpm}$ for 5 minutes to make uniform solution.

\subsection{Drying process}

After the carrier agent formulation, the roselle solution was then dried in tray dryer. The solution was placed in aluminium tray under drying temperature $\left(50{ }^{\circ} \mathrm{C}-70^{\circ} \mathrm{C}\right)$ for 150 minutes. The moisture evaporation was determined by gravimetry (weighing the samples every 15 minutes). The drying process took place with superficial velocity of $0.11 \mathrm{~m} \mathrm{~s}^{-1}$.

\subsection{Drying model}

Thin layer model was used to determine the constant rate of the drying. The thin layer model correspond to the drying phenomenon (Tabel 1). The good fit model was selected by the highest value of coefficient determination $\left(\mathrm{R}^{2}\right)$ and the lowest value of Root Mean Square Deviation (RMSD). The evaluation using POLYMATH 6.1 Educational Free Trial version software.

Table 1. Constant rate of the drying several thin layer model

\begin{tabular}{|c|c|c|}
\hline Model & Model equation & References \\
\hline 1. Newton & $M R=\exp (-k t)$ & $\begin{array}{r}\text { O'Callaghan et al. } \\
\text { [16] }\end{array}$ \\
\hline 2. Page & $M R=\exp \left(-k t^{n}\right)$ & Page \\
\hline $\begin{array}{l}\text { 3. Handerson- } \\
\text { Pabis }\end{array}$ & $M R=a \exp (-k t)$ & $\begin{array}{l}\text { Henderson and } \\
\text { Pabis }\end{array}$ \\
\hline 4. Logaritmic & $M R=a \exp (-k t)+c$ & $\begin{array}{l}\text { Yagcioglu et al. } \\
\text { [19] }\end{array}$ \\
\hline
\end{tabular}

The moisture ratio (dimensionless moisture) could be expressed in equation 5 .

$$
M R=\frac{M_{\mathrm{L}}-\mathbb{M}_{\varepsilon}}{\mathbb{M}_{\mathrm{D}}-\mathbb{M}_{\mathrm{q}}}
$$

where $\mathrm{M}_{\mathrm{t}}$ was the moisture content at time $\mathrm{t}(\mathrm{kg}$ water $/ \mathrm{kg}$ dry solid), $\mathrm{M}_{0}$ was the initial moisture content $(\mathrm{kg}$ water $/ \mathrm{kg}$ dry solid), $\mathrm{M}_{\mathrm{e}}$ was the equilibrium moisture content (kg water/kg dry solid).

The value of equilibrium moisture content of the solution was determined using equation 6 .

$$
M e=(X M e)_{\text {roselle }}+(X M e)_{\text {ma }} \text { 倡todextrin }
$$

Equilibrium moisture content for roselle and maltodextrin.was previously studied [20,21].

\subsection{Antioxidant activity analysis}

The capacity of roselle extracts to inhibit DPPH (free radical) was determined according to the method of Brand-Williams et al. with slight modification [22]. The procedure was done by measured the absorbance of the roselle extract and DPPH solution at $517 \mathrm{~nm}$ using a spectrophotometer. As the control, the blank $(100 \mu \mathrm{L}$ of ethanol in $1.4 \mathrm{~mL}$ of DPPH radical solution) was measured.

Inhibition (\%) was used to express the antioxidant activity, as expressed in equation 7 .

$$
I(\%)=\left[\frac{A_{0}-1}{A_{x}}\right.
$$

where, $A_{s}$ was absorbance of the roselle solution and $A_{o}$ was absorbance of control.

First order reaction was used to describe the anthocyanin and phenolic compound degradation in food product [23]. The anthocyanin and phenolic compound was the source of antioxidant, so the degradation of antioxidant activity following that equation.

$$
\ln \left(\frac{I}{I_{0}}\right)=-k_{i} t
$$

where $\mathrm{I}$ and $\mathrm{I}_{0}$ were antioxidant activity of the sample at time 0 and $\mathrm{t}$. $\mathrm{k}_{\mathrm{i}}$ was the constant rate of antioxidant activity degradation(minute ${ }^{-1}$ ).

Arrhenius model was used to correlate the dependency of $\mathrm{k}_{\mathrm{i}}$ on temperature $(\mathrm{T})$.

$$
k_{i}=k_{0} \exp (-E A / R T)
$$

where Ea was the activation energy $\left(\mathrm{J} \mathrm{mol}^{-1}\right)$, and $\mathrm{R}$ was the gas constant $\left(8.32 \mathrm{~J} \mathrm{~mol}^{-1} \mathrm{~K}^{-1}\right)$ and $\mathrm{k}_{0}$ was the preexponential factor $\left(\right.$ minute $\left.^{-1}\right)$.

\section{Results and Discussion}

\subsection{Addition carrier agent}

The moisture in roselle extract evaporated during the drying process (Fig. 1.). The addition of maltodextrin could speed up the drying rate. The final moisture content after 150 minutes drying process was 0.62 (gram of moisture per gram of dried product) in addition $10 \%$ maltodextrin, while in roselle extract drying without addition of maltodextrin resulted moisture content 2.101 (gram of moisture per gram of dried product). The final moisture content of roselle extract using $10 \%$ maltodextrin was 3.9 times lower than without maltodextrin. This research comparable with another research that resulted the constant rate of the drying 1.7 times higher than without maltodextrin [11]. 


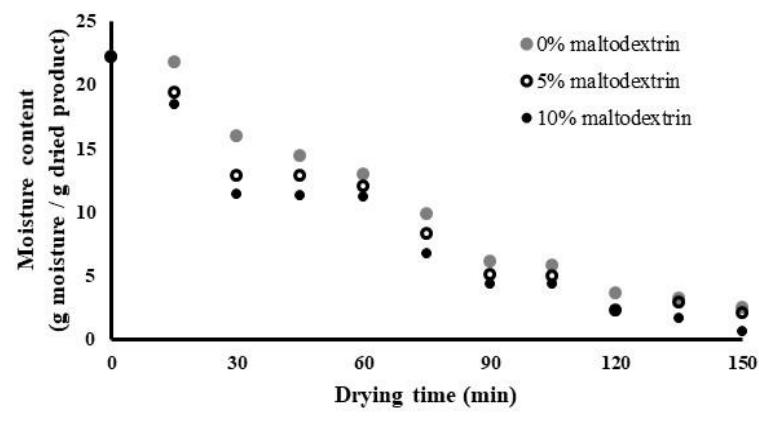

Fig. 1. Effect of addition carrier on moisture content during the drying process

In this research low DE maltodextrin was used as the carrier agent. Addition this carrier agents affected the different final moisture content. The low DE maltodextrin has the less number of ramifications with the hydrophilic groups and not easy to bind with the water molecules from the air [10]. On the other hand, the addition of maltodextrin affected the stickiness surface of roselle extract. The stickiness surface of roselle extract because of low molecular sugar like glucose, sucrose, fructose. Higher concentration of maltodextrin reduces the stickiness surface of the roselle extract [10].

\subsection{Drying temperatures}

The effect of drying temperatures to the moisture content during the drying process was represented in Fig.2. After 150 minutes drying, the drying process that was conducted in higher drying temperature resulted lower moisture content. Drying roselle extract with the drying temperature $70^{\circ} \mathrm{C}$ resulted in the final moisture content of 0.163 (gram of moisture per gram of dried product), while the final moisture content in the drying temperature $50^{\circ} \mathrm{C}$ was 3.8 times higher.

The higher drying temperatures increased constant rate of the drying (Table 2), as also found $\mathrm{n}$ the previous studies [24,25]. The constant rate of the drying at drying temperature $70^{\circ} \mathrm{C}$ was 9.6 times higher than at drying temperature $50^{\circ} \mathrm{C}$. As the comparison, another research resulted constant rate of the drying at drying temperature $70^{\circ} \mathrm{C}$ was 1.6 times higher than at drying temperature $50^{\circ} \mathrm{C}$ [10]. In higher drying temperature, the relative humidity of air is low, driving force for the drying increase and the sensible heat from the hot air used for water evaporation $[25,26,27]$.

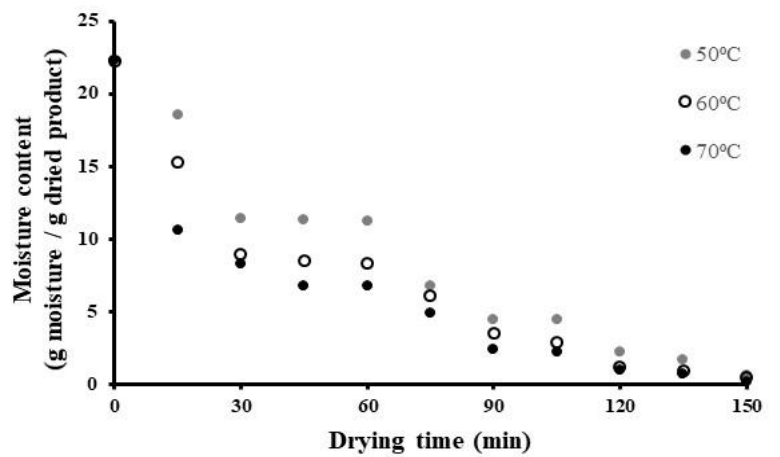

Fig. 2. Effect of drying temperatures on moisture content during the drying process

\subsection{Drying rate constant and model}

Thin layer model was used to determine the drying phenomenon in roselle extract. Based on the Table 1, all the model resulted the $\mathrm{R}^{2}$ value range from 0.924 until 0.971 and RMSD value range from 0.014 until 0.021 . It was indicated that the thin layer model can well represent the roselle extract drying. The $\mathrm{R}^{2}$ value in Page model (no 2) was higher than 0.964 with RMSD value was less than 0.017 . This model can be used to predict the drying rate of roselle extract drying with addition maltodextrin.

Table 2. Constant rate of the drying several thin layer model

\begin{tabular}{|c|c|l|c|c|}
\hline Model & T $\left({ }^{\circ} \mathbf{C}\right)$ & \multicolumn{1}{|c|}{ Constant } & $\mathbf{R}^{2}$ & RMSD \\
\hline \multirow{4}{*}{1} & 50 & $\mathrm{k}: 0.016$ & 0.962 & 0.018 \\
\cline { 2 - 5 } & 60 & $\mathrm{k}: 0.021$ & 0.963 & 0.017 \\
\cline { 2 - 5 } & 70 & $\mathrm{k}: 0.027$ & 0.924 & 0.023 \\
\hline \multirow{4}{*}{2} & 50 & $\mathrm{k}: 0.011, \mathrm{n}: 1.083$ & 0.964 & 0.017 \\
\cline { 2 - 5 } & 60 & $\mathrm{k}: 0.039, \mathrm{n}: 0.852$ & 0.971 & 0.015 \\
\cline { 2 - 5 } & 70 & $\mathrm{k}: 0.110, \mathrm{n}: 0.646$ & 0.973 & 0.014 \\
\hline \multirow{4}{*}{3} & 50 & $\mathrm{k}: 0.017, \mathrm{a}: 1.014$ & 0.962 & 0.018 \\
\cline { 2 - 5 } & 60 & $\mathrm{k}: 0.020, \mathrm{a}: 0.958$ & 0.966 & 0.016 \\
\cline { 2 - 5 } & 70 & $\mathrm{k}: 0.024, \mathrm{a}: 0.903$ & 0.938 & 0.021 \\
\hline \multirow{4}{*}{4} & 50 & $\begin{array}{l}\mathrm{k}: 0.012, \mathrm{a}: 1.130 \\
\mathrm{c}:-0.145\end{array}$ & 0.969 & 0.016 \\
\cline { 2 - 5 } & 60 & $\begin{array}{l}\mathrm{k}: 0.020, \mathrm{a}: 0.960 \\
\mathrm{c}:-0.004\end{array}$ & 0.966 & 0.016 \\
\cline { 2 - 5 } & 70 & $\begin{array}{l}\mathrm{k}: 0.030, \mathrm{a}: 0.880 \\
\mathrm{c}: 0.049\end{array}$ & 0.942 & 0.020 \\
\hline
\end{tabular}

The drying curves in the form of moisture ratio versus drying time (experiment and model) were depicted in Figure 3. Page model was used to describe the drying phenomenon of food product : bitter melon [28], carrot [29], and seaweed [30]. Page model showed a good fit curves to roselle extract drying with maltodextrin. 

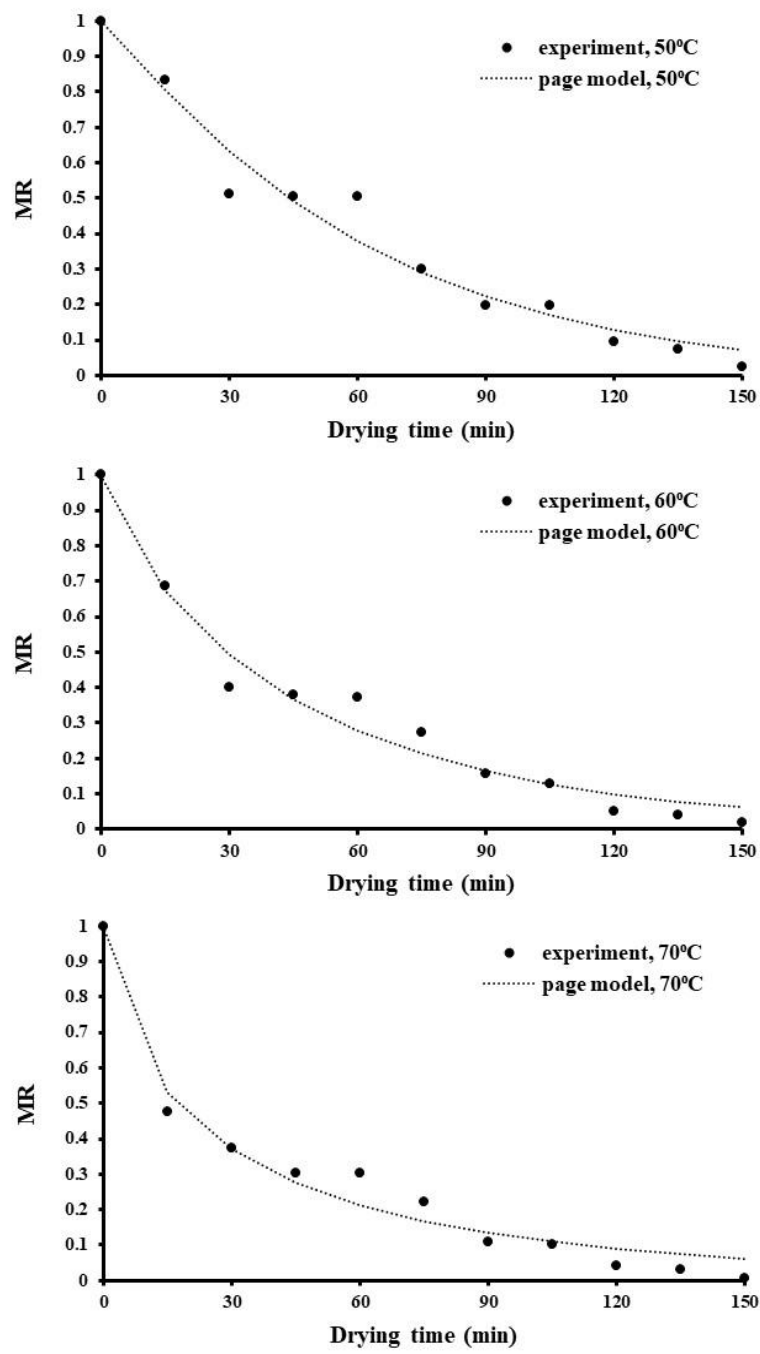

Fig. 3. Comparison of experimental and page model in moisture ratio curves of roselle extract drying at various drying temperature

\subsection{Antioxidant Activity Degradation}

The antioxidant activity in roselle extract drying with addition $10 \%$ maltodextrin was expressed as \% inhibition. The degradation of antioxidant activity was faster in higher drying temperature and longer drying time (Figure 4). Anthocyanin as the antioxidant component in roselle extract was thermal sensitive $[23,31,32]$. The antioxidant activity degradation in roselle extract was caused by the thermal degradation of anthocyanin compound.

The constant rate of antioxidant activity degradation in drying temperature $70^{\circ} \mathrm{C}$ was 2.14 times higher than in drying temperature $50^{\circ} \mathrm{C}$ (see Table 3). As the comparison, the constant rate of antioxidant activity degradation in roselle extract drying with maltodextrin was 18 times lower than constant rate of antioxidant activity degradation in beetroot and green pepper at the same temperature $\left(70^{\circ} \mathrm{C}\right)[33]$. Antioxidant activity in roselle extract was reduced $40.1 \%$ after thermal process $\left(90^{\circ} \mathrm{C}\right)$ for 2 hours [34]. Addition maltodextrin in roselle extract drying could shorten the drying time as well as decreased the antioxidant activity degradation.

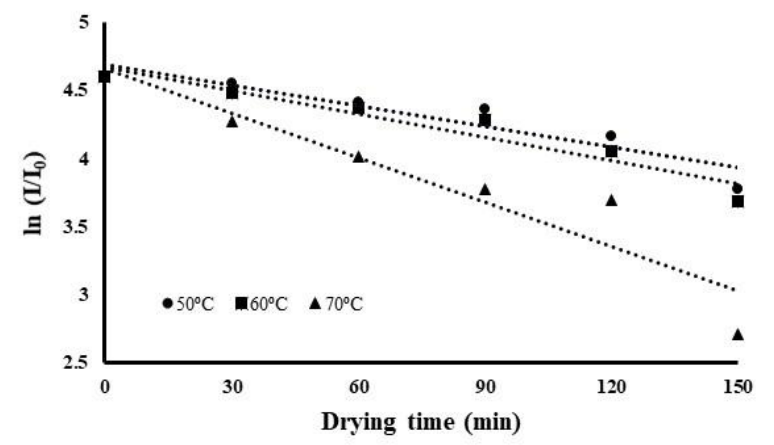

Fig. 4. The antioxidant activity degradation at various drying conditions

Arrhenius model was used to correlate the dependency of $\mathrm{k}_{\mathrm{i}}$ on temperature $(\mathrm{T})$. The value of Arrhenius constants were listed in Table 3 . Using the value of Ea and $\mathrm{K}_{0}$, the value of constants rate of the antioxidant activity degradation under various temperature can be predicted.

Table 3. Constant rate of the antioxidant activity degradation

\begin{tabular}{|c|c|c|c|c|}
\hline $\left.\mathbf{T} \mathbf{~}^{\mathbf{0}} \mathbf{C}\right)$ & $\mathbf{k}_{\mathbf{i}}\left(\mathbf{m i n}^{-\mathbf{1}}\right)$ & $\mathbf{R}^{\mathbf{2}}$ & $\mathbf{K}_{\mathbf{0}} \mathbf{x} \mathbf{1 0}$ & $\mathbf{E a}(\mathbf{K j} / \mathbf{m o l})$ \\
\hline 50 & 0.005 & 0.927 & \multirow{3}{*}{1.932} & \multirow{2}{*}{34.754} \\
\cline { 1 - 3 } 60 & 0.006 & 0.949 & \multirow{2}{*}{1.932} & \\
\hline 70 & 0.011 & 0.911 & & \\
\hline
\end{tabular}

\section{Conclusions}

The effect of addition carrier agent in constant rate and antioxidant activity were studied. Low DE maltodextrin is not easy to bind with the water molecules from the air and reduce stickiness surface of roselle extract. Page model showed good fit curves with $\mathrm{R}^{2}$ value in Page model (no 2) was higher than 0.964 with RMSD value was less than 0.017 . The values of constant rate for drying at drying temperatures $50^{\circ} \mathrm{C}-70^{\circ} \mathrm{C}$ ranged from 0.011-0.110 $\mathrm{min}^{-1}$. The degradation of antioxidant activity was faster in higher drying temperature and longer drying time. Addition of maltodextrin could shorten the drying time and decreased the antioxidant activity degradation

This study was supported by Directorate General of Higher Education (DIKTI) under Competency Grant (Hibah Kompetensi) for 2017-2018.

\section{References}

1. P. J. Tsai, J. McIntosh, P. Pearce, B. Camden, and B. R. Jordan, Food Res. Int., 35 (4), 351-356 (2002)

2. M. Fullerton, J. Khatiwada, J. U. Johnson, S. Davis, and L. L. Williams, J. Med. Food, 14 (9), 950-956 (2011)

3. T. Okoko and D. Ere, Asian Pac. J. Trop. Med., 5 (1), 33-36 (2012) 
4. E. M. Abdou, H. S. Hafez, E. Bakir, and M. S. A. Abdel-mottaleb, Spectrochim. Acta Part A Mol. Biomol. Spectrosc., 115 202-207 (2013)

5. P.-L. Tee, S. Yusof, and S. Mohamed, Nutr. Food Sci., 32 (1), 17-20 (2002)

6. S. Cid-Ortega and J. A. Guerrero-Beltran, J. Food Res., 3 (5), 83 (2014)

7. P. Chumsri, A. Sirichote, and A. Itharat, J. Sci. Technol., 30 (Suppl.1) 133-139 (2008)

8. M. A. Youssef, A. A. El kady, and K. S. Nagy, Middle East J. Agric. Res., 4 (4), 697-706 (2015)

9. A. N. Al-Baarri, A. T. Suminar, and A. M. Legowo, Potravinarstvo 11 (1), (2017)

10. S. Singh and D. Dixit, Int. J. Appl. Eng. Technol., 4 ( 1), 1-8 (2014)

11. M. Djaeni, F. D. Utari, and A. C. Kumoro, AIP Conference Proceedings, 1823 20045-1-20045-6 (2017)

12. M. C. P. de A. Santiago, R. I. Nogueira, D. R. S. F. Paim, A. C. M. S. Gouvêa, R. L. de O. Godoy, F. M. Peixoto, S. Pacheco, and S. P. Freitas, LWT - Food Sci. Technol., 73, 551-556 (2016)

13. Duangmal, B. Saicheua, and S. Sueeprasan, LWT Food Science and Technology, 41 (8), 1437-1445 (2008)

14. A. Ekpong, W. Phomkong, and E. Onsaard, Int. Food Res. J., 23 (1). 300-308 (2016)

15. K. A. Selim, K. E. Khalil, M. S. Abdel-Bary, and N. A. Abdel-Azeim, J. Food Sci. Technol., 7-20 (2008)

16. O'Callaghan J R., Menzies D J and Bailey P H J., Agric. Eng. Res 16 (3), 223-244 (1971)

17. G. Page, MS Thesis Submitted to Purdue University West Lafayette, IN, USA (1949)

18. S. M. Henderson and S. Pabis, J. Agric. Eng. Res., 6, 169-174 (1961)

19. A .Yagcioglu, A. Degirmencioglu and F. Cagatay, Proceedings of the 7th International Congress on Agricultural Mechanization and Energy, 565-569 (1999)

20. Langová, D. Jaisut, R. Thuwapanichayanan, C. Phowong, J. Štencl, D. Jovanovic, J. Fryè, and V. Vlášek, Acta Univ. Agric. Silvic. Mendelianae Brun., 61 (6), 1769-1777 (2013)

21. Y. Roos and M. Karel, Biotechnol. Prog., 7 (20), 49-53 (1991)

22. W. Brand-Williams, M. E. Cuvelier, and C. Berset, 28 (1), 25-30 (1995)

23. Z. Zori, V. Dragovc-Uzelac, S. Pedisic, Z. Kurtanjek, and I. E. Garofulic, Food Technol.Biotechnol, 52 (1), 101-108 (2014)

24. M. Djaeni, S. B. Sasongko, A. Prasetyaningrum, X. Jin, and A. J. van Boxtel, Int. J. Food Eng., 8 (3), 121 (2012)

25. M. Djaeni and D. A. Sari, Procedia Environmental Sciences 23, 2-10 (2015)
26. M. Djaeni, D. Ayuningtyas, N. Asiah, H. Hargono, R. Ratnawati, W. Wiratno, and J. Jumali, Reaktor 14, ( 3), 173-178 (2013)

27. M. Djaeni, D. Anggoro, G. W. Santoso, D. Agustina, N. Asiah, and C. L. Hii, Adv. J. Food Sci. Technol., 6 (7), 833-838 (2014)

28. J. Chen, Y. Zhou, S. Fang, Y. Meng, X. Kang, X. $\mathrm{Xu}$, and $\mathrm{X}$. Zuo, Advance Journal of Food Science and Technology 5 (9), 1214-1219 (2013)

29. I. Doymaz, Journal of Food Engineering 61 (3), 359-364 (2004)

30. A. Fudholi, M. Y. Othman, M. H. Ruslan, M. Yahya, A. Zaharim, and K. Sopian, Proceedings of the 4th WSEAS international conference on Energy and development - environment - biomedicine, 129133 (2011)

31. M. Cisse, F. Vaillant, O. Acosta, D. M. Claudie, and M. Dornier, J. Agric. Food Chem., 57, 6285-6291 (2009)

32. A. Sinela, N. Rawat, C. Mertz, N. Achir, H. Fulcrand, and M. Dornier, Food Chem., 214, 234 241 (2017)

33. V. Eyarkai Nambi, R. K. Gupta, S. Kumar, and P. C. Sharma, Journal of Food Science and Technology, 53 (7) 3073-3082 (2016)

34. P.-J. Tsai and H.-P. Huang, Food Research International 37 (4), 313-318 (2004) 